\title{
負制約の等価変換による問題解決の基礎理論
}

\section{A Theoretical Foundation of Problem Solving by Equivalent Trans- formation of Negative Constraints}

\author{
小池 英勝 \\ 北海道大学大学院工学研究科システム情報工学専攻 \\ Division of System and Information Engineering, Hokkaido University \\ koke@cims.hokudai.ac.jp \\ 赤間 清 北海道大学情報メディア教育研究総合センター \\ Kiyoshi Akama Center for Information and Multimedia Studies, Hokkaido University \\ akama@cims.hokudai.ac.jp \\ 馬淵 浩司 \\ 岩手県立大学ソフトウェア情報学部 \\ Hiroshi Mabuchi \\ Dept. of Software and Information Science, Iwate Prefectural University \\ mabu@soft.iwate-pu.ac.jp \\ 岡田 浩一 \\ 日本電信電話株式会社情報流通プラットフォーム研究所 \\ NTT Information Sharing Platform Laboratories, NTT \\ koichi@slab.ntt.co.jp \\ 繁田 良則 \\ 東芝システム LSI 技術研究所 \\ System ULSI Engineering Laboratory, Toshiba Corporation \\ yoshinori.shigeta@toshiba.co.jp
}

keywords: negation, negative constraint, equivalent transformation, declarative description, resolution.

\section{Summary}

Representation and computation of negation is very important in problem solving in various application domains. The purpose of this paper is to propose a new approach to negation. While most theories for negation are based on the logic paradigm, this theory is constructed based on the equivalent transformation (ET) computation model, since the ET model provides us with "decomposability of programs," i.e., a program in the ET model is a set of ET rules and can be synthesized by generating each ET rule independently of other ET rules.

To represent negation in the ET model, a constraint is introduced as a pair of an object and a domain. A constraint becomes true when the object is specialized to a ground object within the domain. A negative constraint has a domain that is the complement of the meaning of the corresponding declarative description. Computation of negation in the ET paradigm is realized by equivalent transformation of declarative descriptions including negative constraints.

For each negative constraint in a definite clause, a new declarative description is produced and transformed equivalently. When it is transformed to a set of unit clauses, the negative constraint is solved. Each unit clause returns a simple constraint to the "caller" clause. This paper proves two theorems that provide a basis for such equivalent transformation of negative constraints.

\section{1.まえ がき}

論理プログラミングの分野での最も基礎的な問題は， 確定節集合とアトムのペアによって定まる [Lloyd 87] . SLDレゾリューションの理論は, このクラスの問題を解 く方法を基礎付けている.Prolog の成功により，SLDレ ゾリューションの有効性は広く認識され，レゾリューショ ン形式による問題解決の理論化は, 論理プログラミング の基本的な方法となっている．しかし，SLDレゾリュー ションの理論を基礎として, 問題解決のための効率的な プログラムを構築するのは, 実は一般には決して簡単で はないのである . 最も重大な問題の1つは計算の制御で ある . SLDレゾリューションによる計算の効率は , 計算
の制御に大きく依存するが, 計算の制御を適切に設定す るのは一般には容易ではない. 多数の問題を解くために 共通に利用できる計算の制御の発見はさらに困難である .

SLDレゾリューションの理論を基礎としたプログラム 作成の困難の少なからざる部分が，等価変換パラダイム によって克服できる.等価変換パラダイムでは,等価変換 ルールを繰り返し適用し，問題を簡単化することによっ て問題を解く [赤間 97 , 赤間 $98 \mathrm{e}$ ] . 乥こでは, プログラム とは, 等価変換ルールの集合であり，等価変換ルールとい う部品を集めることによって，プログラムを作ることがで きる.プログラムを作るという難しい作業が，兰れを構成 するルールを作るという，より簡単な作業に分解される のである [Akama 01a] .こうして作られたプログラムは， 
新しいデータ構造を導入したり，新たなルールを追加する ことによって比較的小さなコストで改善できる [畑山 97] これはさらに, プログラムの自動生成の理論やプログラ ム自動生成システムの作成 [Akama 01a, Koike 01] を可 能にしている。

等価変換パラダイムでは, ある問題を解くためのすべ ての正当な手続きを，基本的な等価変換の組み合わせに よって説明する．この方法は広範な問題に適用できる． SLD レゾリューションの正当性もまた, アンフォールド 变換という等価変換の組み合わせで容易に証明できる [赤 間 98d] . SLDレゾリューションの理論の機能は等価変換 の理論で代替できる . 逆に , SLD レゾリューションの理 論は等価変換が提供する計算の組み合わせをすべて可能 とすることができない [赤間 $98 \mathrm{~d}$ ] .さらに，等価変換の 理論は, 任意の等価変換を自由に組み合わせて正当な手 続きを作り出すことができるので, アンフォールド変換 に縛られたSLDレゾリューションの理論とは対照的に， 手続きを柔軟に拡張できる、もし等価変換を採用しアン フォールド変換以外の等価変換を用いれば, 計算効率の 改善の可能性 [赤間 98b] が開け, アンフォールド变換よ りも適用範囲の狭いルールを用いれば, 計算制御の改善 が期待できる [Koike 00] .

レゾリューションタイプの理論ではなく，等価変換を 基礎とした理論を構筑することが, 問題解決とプログラ ム生成の研究を進展させるために有効と考えられる .こ のような有用な理論体系を，否定を含む問題クラスに拡 大する方法を基礎付けるのが本論文の目的である .

本論文では, 次の 2 つの提案を行なう .

(1) 否定を含む問題を表現するための方法の提案

(2) 否定を含む問題を計算するための基礎となる等価 变換ルールの提案

ここで注意してほしいのは, 論理プログラミングにおけ る研究と等価変換パラダイムのもとでの研究では,「ゲー ムのルール」が違うことである. 論理プログラミングで は, 問題の記述は論理式に限定されているのに対して, 等 価変換パラダイムでは, 集合を記述する任意の式 (宣言的 記述と呼ばれる) が問題記述として用いられる . 従って, 本論文では, 否定を含む問題を表現する宣言的記述のク ラスが提案される．また論理プログラミングでは, 論理 式を計算する一連の手続きか議論されるが, 等価変換パ ラダイムでは宣言的記述を処理する基本的な等価変換を 発見する必要がある .

本論文の構成を示す． 2 章では，制約つき宣言的記述， 負制約, 意味の定義を与える. 3 章では, 等価変換による 計算について述へ，変換の正当性を証明するための基礎 となる命題を証明する.4 章では, 負制約の本格的な等 価変換を引き起こすための準備となる等価変換 (負制約 における制約対象の繰り込み)のために必要な定理を証 明する. 5 章では, 負制約の参照記述を等価変換し, 負 制約を解消するために必要な定理を証明する．6 章では，
負制約の等価変換によって問題を解決する例を与える .7 章では, 本論文の方法と論理プログラミングの方法を比 較する. 8 章では, 本論文のまとめを述べる .

\section{2. 制約つき宣言的記述}

\section{$2 \cdot 1$ 特殊化システム}

適切なデータ構造を採用することによって, 計算効率 は著しく改善できる可能性がある，従って，多くのデー 夕構造を統合的に扱う理論のもとで, データ構造の変更 を行える理論体系が , プログラム生成にとって有効であ る [赤間 98a] . 等価変換に基づく問題解決の理論では, 各 知識表現が扱う対象と乥れへの操作がなす構造を“特殊 化システム”という数学的構造として捉える*1. これに より多くのデータ構造に共通の構造を明快に理論化する ことができる ${ }^{* 2}$.

\section{【定義 1】【特殊化システム】}

特殊化システムとは, fill 集合 $\mathcal{A}, \mathcal{G}, \mathcal{S}$ と写像 $\mu: \mathcal{S} \rightarrow$ $\operatorname{partial\_ map}(\mathcal{A})$ からなる 4 項組 $\Gamma=\langle\mathcal{A}, \mathcal{G}, \mathcal{S}, \mu\rangle$ で, 次 の条件を満たすものである.但し, partial_map $(\mathcal{A})$ は $\mathcal{A}$ 上の部分写像全体の集合を表す . $\mu\left(s_{1}\right) \circ \mu\left(s_{2}\right)$ は 2 つの 部分写像 $\mu\left(s_{1}\right)$ と $\mu\left(s_{2}\right)$ の合成写像である.$\mu(s)(a)$ は $\mathcal{A}$ 上の部分写像 $\mu(s)$ の $a$ における値 $(\mathcal{A}$ の元) を意味する .

(1) $\forall s_{1}, s_{2} \in \mathcal{S}, \exists s \in \mathcal{S}: \mu(s)=\mu\left(s_{1}\right) \circ \mu\left(s_{2}\right)$

(2) $\exists s \in \mathcal{S}, \forall a \in \mathcal{A}: \mu(s)(a)=a$

(3) $\mathcal{G} \subseteq \mathcal{A}$

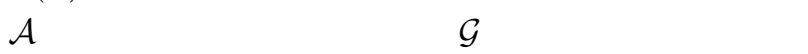
ト，S の元を特殊化と呼ぶ .

$\theta \in \mathcal{S}$ のとき,$\mu(\theta)(a)$ を後置記法で $a \theta$ と表すことが ある $. a \theta=b$ を満たす $b$ が存在するとき， $\theta$ は $a$ に適用 可能であるという $. a \theta=b$ のとき, $a$ は $\theta て ゙ ~ b$ に特殊化 されるという.さらに $b$ が基礎オブジェクトであるとき， $b$ は $a$ の基礎例であるという . $a$ の基礎例全体の集合を $r e p(a)$ で表す.$\theta \in \mathcal{S}$ が $\mathcal{A}$ の部分集合 $B$ に適用可能で あるとは, $\theta$ が $B$ の任意の元に適用可能なことである . 兴のとき, $B \theta=\{b \theta \mid b \in B\}$ と定義する．

定義 1 は, 特殊化システムを公理的に定義*3している. 集合 $\mathcal{A}, \mathcal{G}, \mathcal{S}$ と写像 $\mu: \mathcal{S} \rightarrow \operatorname{partial}$ map $(\mathcal{A})$ は，定義 1 の条件 $(1) \sim(3)$ を満たす任意のものか許される .これ によって , 特殊化システムは, 非常に広い範囲の知識表 現系を捉えることができる .

\section{$2 \cdot 2$ 制約つき宣言的記述}

$\Gamma$ 上の制約とは, $\mathcal{A}$ の元 $a$ と $\mathcal{G}$ の部分集合 $G$ のペ ア $(a, G)$ である.制約 $(a, G)$ は $a \in \mathcal{G}$ のとき基礎制約で あるという . 基礎制約 $(g, G)$ は $g \in G$ のとき真であり， $g \notin G$ のとき偽であるという. 特殊化 $\theta$ が制約 $(a, G)$ に

\footnotetext{
*1 特殊化システムの具体例は [赤間 $98 \mathrm{a}$, 赤間 $98 \mathrm{c}$ ] などを参照. *2 項や文字列, 制約, マルチセットなどの他, XML のデータ

構造などにも応用されている [Wuwongse 01] .

$* 3$ 写像 $\mu$ の定義についての説明を付録で述べる.
} 
適用可能なのは, $\theta$ が $a$ に適用可能なときであり, 弚の適 用結果 $(a, G) \theta$ は制約 $(a \theta, G)$ である.このとき， $(a, G)$ は $\theta$ によって $(a \theta, G)$ に特殊化されるという .

$\mathcal{A}$ のオブジェクト $H$ と，A のオブジェクトまたは $\Gamma$ 上の制約 $B_{1}, B_{2}, \cdots, B_{n}$ からなる式*4

$$
H \leftarrow B_{1}, B_{2}, \cdots, B_{n}
$$

を， $\Gamma$ 上の制約つき確定節と呼ぶ． $H$ をヘッド， $B_{1}, B_{2}$, $\cdots, B_{n}$ の全体をボディと呼ぶ . 制約つき確定節 $C$ のヘッ ドをhead $(C)$ ，ボディ中のオブジェクトの集合を $o b j(C)$ ， ボディ中の制約の集合を $\operatorname{const}(C), \operatorname{obj}(C)$ と $\operatorname{const}(C)$ の和集合を body $(C)$ で表す .ヘッドまたはボディの構 成要素として使われるオブジェクトをしばしばアトムと 呼引゙．

基礎オブジェクトまたは基礎制約だけからなる制約つ き確定節を基礎節と呼ぶ． $\Gamma$ 上の基礎節全体の集合を Gclause $(\Gamma)$ で表す.制約つき確定節

$$
C=\left(H \leftarrow B_{1}, B_{2}, \cdots, B_{n}\right)
$$

と特殊化 $\theta$ に対して，もし $\theta$ が $H, B_{1}, B_{2}, \cdots, B_{n}$ の すべてに適用可能であるならば， $\theta$ は $C$ に適用可能で， 適用結果 $C \theta$ は

$$
C \theta=\left(H \theta \leftarrow B_{1} \theta, B_{2} \theta, \cdots, B_{n} \theta\right)
$$

であると定義する . $C \theta=C^{\prime}$ のとき, $C^{\prime}$ は $C$ の例であ るという . 基礎節 $C^{\prime}$ が $C$ の例であるとき， $C^{\prime}$ は $C$ の 基礎例であるという .

$\Gamma$ 上の制約つき宣言的記述 ${ }^{*}$ とは， $\Gamma$ 上の制約つき確 定節の集合である．本論文では，制約つき確定節をしば しば単に確定節，あるいは，節と呼ぶことがある．同樣 に，制約つき宣言的記述を，単に宣言的記述と呼ぶこと がある

\section{$2 \cdot 3$ 正制約と負制約による表現}

制約 $(a, G)$ の $a$ を制約対象， $G$ を制約領域と呼ぶ。制 約領域は $\mathcal{G}$ の任意の部分集合が可能なので,$\Gamma$ 上のある 宣言的記述 $Q$ の意味 $\mathcal{M}(Q)$ (定義 3$)$ の関数として決まる 集合を制約領域として用いることができる.このように 制約領域として他の宣言的記述の意味の関数を使った制 約を依存制約と呼び，これらの制約は他の宣言的記述 $Q$ を「参照している」という．Qははこの制約の参照記述と呼 ばれる。例えば，制約領域として $\mathcal{M}(Q)$ や $\mathcal{G}-\mathcal{M}(Q)$ をとれば，制約 $(a, \mathcal{M}(Q)) や(a, \mathcal{G}-\mathcal{M}(Q))$ が得られ る.これらを $[a \in \mathcal{M}(Q)] や[a \notin \mathcal{M}(Q)]$ とも書き，乥 れ光れ正制約，負制約と呼ぶ。

依存制約は，制約つき宣言的記述の表現力を大きく拡 大する.特に負制約は，否定を表現するのに直接的に使

\footnotetext{
*4 Prolog にならって , 最後にピリオドをつけて表記する場合 もある

*5 論理プログラムは, 節の宣言的解釈と手続き的解釈に基づい て，宣言的側面と手続き的側面を兼ね備えた存在である．弚れ に対して，この「宣言的記述」は，意味を記述するという宣言 的な側面だけを持つ．乥こで本論文では, 誤解を避けるために， 従来の「宣言的プログラム」というネーミングを避け,宣言的 記述」と呼ぶ .
}

うことができる，例えば，論理パラダイムにおける否定 を含む節

$$
\operatorname{even}(X) \leftarrow \operatorname{integer}(X), \neg \text { odd }(X) .
$$

は，宣言的記述 $Q$ で odd 述語を記述しておけば， even $(X) \leftarrow$ integer $(X),[\operatorname{odd}(X) \notin \mathcal{M}(Q)]$.

という制約つき確定節として表現できる.

\section{$2 \cdot 4$ 制約つき宣言的記述の意味}

制約つき宣言的記述の意味を定義する．

まず， $\Gamma$ 上の宣言的記述 $P$ に対して，写像 $T_{P}: 2^{\mathcal{G}} \rightarrow$ $2^{\mathcal{G}}$ を定義する．これは，定義 3 において，宣言的記述の 意味を求める際に使用される.

\section{【定義 2】【写像 $T_{P}$ 】}

$\Gamma=\langle\mathcal{A}, \mathcal{G}, \mathcal{S}, \mu\rangle$ とする . 写像 $T_{P}: 2^{\mathcal{G}} \rightarrow 2^{\mathcal{G}}$ を，任意の $I \subseteq \mathcal{G}$ に対して

$$
\begin{aligned}
T_{P}(I) \stackrel{\text { def }}{=}\{\operatorname{head}(C \theta) \mid & C \in P, \\
& \theta \in \mathcal{S}, \\
& \operatorname{obj}(C \theta) \subseteq I, \\
& \operatorname{const}(C \theta) \subseteq \operatorname{Tconst}(\Gamma), \\
& C \theta \in \operatorname{Gclause}(\Gamma)\}
\end{aligned}
$$

で定義する . 但し , Tconst $(\Gamma)$ は

$$
\operatorname{Tconst}(\Gamma)=\{(g, G) \mid g \in G \subseteq \mathcal{G}\}
$$

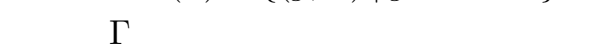

次に写像 $T_{P}$ を使って，宣言的記述 $P$ の意味を定義 する。

\section{【定義 3】【宣言的記述の意味】}

$P$ を $\Gamma$ 上の宣言的記述とする . 宣言的記述 $P$ の意味 $\mathcal{M}(P)$ は,

$$
\mathcal{M}(P) \stackrel{\text { def }}{=} \bigcup_{n=1}^{\infty}\left[T_{P}\right]^{n}(\emptyset)
$$

で定義される．但し，りは空集合を表す．

\section{$2 \cdot 5$ 層状プログラムとの関係}

以上で定義された宣言的記述は, 論理パラダイムにお ける層状プログラムに近い . しかし層状プログラムが論 理式 (節の平坦な集合)であるのに対して，宣言的記述は 論理式ではなく，集合を記述する式であり，初めから層 状をしている [Akama 01b] . また，上下関係のある $2 つ$ の宣言的記述が共通の述語をもっていたとしても，乥れ らは意味の算定で独立に扱われる。

層状プログラムのクラスは, 理論的には簡単であると 考えられることもあるが, プログラム合成について考え ると，これから解決すべき課題は山積している.

\section{3. 基礎的な変換の等価性}

\section{$3 \cdot 1$ 等価変換による解法}

任意の特殊化システム上の制約つき宣言的記述と光の意 味を 2 章で定義した . 等価変換に基づく問題解決では, 宣 
言的記述 $P$ の意味 $\mathcal{M}(P)$ の関数 (即ち $\pi(\mathcal{M}(P))$ の形) によって求めるべきものを定式化する ${ }^{* 6} . P_{1}$ から $P_{2}$ に 宣言的記述を等価変換するとは, $\mathcal{M}\left(P_{1}\right)=\mathcal{M}\left(P_{2}\right)$ を満 たす条件のもとで $P_{1}$ を変形し $P_{2}$ を得ることである．等 価変換しても $\mathcal{M}(P)$ は変化せず，したがって $\pi(\mathcal{M}(P))$ も変化しないので, 簡単化された宣言的記述から正しく 問題の答えを求めることができる.

\section{$3 \cdot 2$ 等価性のための基礎的な命題}

〈命題 1〉 $P, P_{1}, P_{2}$ を $\Gamma$ 上の制約つき宣言的記述と する . 任意の $x \subseteq \mathcal{G}$ に対して $T_{P_{1}}(x)=T_{P_{2}}(x)$ ならば， $\mathcal{M}\left(P \cup P_{1}\right)=\mathcal{M}\left(P \cup P_{2}\right)$ が成り立つ.

本論文のすべての命題と定理の証明は付録で述べる .

\section{$3 \cdot 3$ 制約の置き換え}

〈命題 2〉 $P$ を $\Gamma$ 上の制約つき宣言的記述， $B_{i}$ を制 約 $(a, G), B_{i}^{\prime}$ を制約 $\left(a^{\prime}, G^{\prime}\right), C$ と $C^{\prime}$ を $\Gamma$ 上の制約つ き確定節

$$
\begin{aligned}
& C=\left(H \leftarrow B_{1}, B_{2}, \cdots, B_{i-1}, B_{i}, B_{i+1}, \cdots, B_{n}\right) \\
& C^{\prime}=\left(H \leftarrow B_{1}, B_{2}, \cdots, B_{i-1}, B_{i}^{\prime}, B_{i+1}, \cdots, B_{n}\right)
\end{aligned}
$$

とする .もし任意の特殊化 $\theta \in \mathcal{S}$ に対して $a \theta \in G$ と $a^{\prime} \theta \in G^{\prime}$ が同値ならば，

$$
\mathcal{M}(P \cup\{C\})=\mathcal{M}\left(P \cup\left\{C^{\prime}\right\}\right)
$$

が成り立つ。

\section{4. 負制約における制約対象の繰り込み}

\section{$4 \cdot 1$ 新しい述語の導入}

特殊化システム $\Gamma$ 上のオブジェクトが, 述語と引数か らなる $p\left(t_{1}, t_{2}, \cdots, t_{n}\right)$ の形であることを仮定する.$P$, $Q$ を $\Gamma$ 上の宣言的記述， $a$ を $\Gamma$ 上のオブジェクトとす る.$b$ は $\Gamma$ 上のオブジェクトの值をとる変数とする.$P$ の節 $C$ は, 制約 $[a \notin \mathcal{M}(Q)]$ をボディに含むとする .こ のとき, $a$ の述語を新しい述語に変更したオブジェクト $\phi(a)$ を用いて, 新しい宣言的記述 $Q \cup\{\phi(a) \leftarrow a\}$ を作 り，乥れを用いて制約 $[a \notin \mathcal{M}(Q)]$ を新たな制約

$$
[\phi(a) \notin \mathcal{M}(Q \cup\{\phi(a) \leftarrow a\})]
$$

に書き直すことを考える .この変換を行なうための準備 を行なう.

$a$ に出現する述語を $p_{1} \in R$ ，すでに $Q$ または $a$ て使 われている述語全体の集合を $R^{\prime} \subseteq R$ とする $. R-R^{\prime}$ に 属する述語 (新述語) を $p_{2}$ とする．弚のような述語は $R$ を十分大きい集合 $* 7$ に前もってしておけば必ず存在する． 述語を $R-\left\{p_{2}\right\}$ に限定してできる $\mathcal{A}, \mathcal{G}$ の部分集合を， 乥れ光れ $\mathcal{A}_{0}, \mathcal{G}_{0}$ とする . 述語を $\left\{p_{1}\right\}$ に限定してでき る $\mathcal{A}, \mathcal{G}$ の部分集合を，光れ光れ $\mathcal{A}_{1}, \mathcal{G}_{1}$ とする . 述語

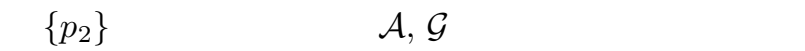
$\mathcal{A}_{2}, \mathcal{G}_{2}$ とする. 写像 $\phi: \mathcal{A}_{1} \rightarrow \mathcal{A}_{2}$ は述語名だけを新し

*6 この定式化の例は 6 章を参照.

*7 例えば可算無限集合にすればよい.
くする変換とする

$$
\phi\left(p_{1}\left(t_{1}, t_{2}, \cdots, t_{n}\right)\right)=p_{2}\left(t_{1}, t_{2}, \cdots, t_{n}\right)
$$

このとき，写像 $\phi$ に対して次の性質が成り立つ。

(1) $\phi: \mathcal{A}_{1} \rightarrow \mathcal{A}_{2}$ は全単射*8 である

(2) すべての $x \in \mathcal{A}_{1}$ に対して , $\phi(x) \theta=\phi(x \theta)$

(3) $\phi\left(\mathcal{G}_{1}\right)=\mathcal{G}_{2}$

本論文の以下の命題や定理では, 本節の $\phi, \mathcal{A}_{0}, \mathcal{A}_{1}, \mathcal{A}_{2}$, $\mathcal{G}_{0}, \mathcal{G}_{1}, \mathcal{G}_{2}$ の定義を仮定する .

\section{$4 \cdot 2$ 制約対象の繰り込み}

負制約の制約対象の情報を，参照記述に繰り込む等価 変換を導入する . これは負制約を処理するための出発点 となる変換である．以降では， $Q^{\prime}=\{\phi(a) \leftarrow a\}$ とする .

〈命題 3$\rangle \mathcal{M}(Q \cup\{\phi(a) \leftarrow a\}) \cap \mathcal{G}_{0}=\mathcal{M}(Q)$

〈命題 4〉 $\mathcal{M}(Q \cup\{\phi(a) \leftarrow a\}) \cap \mathcal{G}_{2}$

$$
=\phi(\mathcal{M}(Q) \cap \operatorname{rep}(a))
$$

以上より, 次の命題が得られる .

〈命題 5〉 $\mathcal{M}(Q \cup\{\phi(a) \leftarrow a\})$

$$
=\mathcal{M}(Q) \cup \phi(\mathcal{M}(Q) \cap \operatorname{rep}(a))
$$

これを用いれば，制約対象の情報を参照記述の中に繰 り込むための定理が証明できる .

[ 定理 1] (繰り込み变換) $P, Q, Q^{\prime}=\{\phi(a) \leftarrow a\}$ を $\Gamma$ 上の制約つき宣言的記述， $B_{i}$ を負制約 $[a \notin \mathcal{M}(Q)]$ ， $B_{i}^{\prime}$ を負制約 $\left[\phi(a) \notin \mathcal{M}\left(Q \cup Q^{\prime}\right)\right], C$ と $C^{\prime}$ を $\Gamma$ 上の制 約つき確定節

$$
\begin{aligned}
& C=\left(H \leftarrow B_{1}, B_{2}, \cdots, B_{i-1}, B_{i}, B_{i+1}, \cdots, B_{n}\right) \\
& C^{\prime}=\left(H \leftarrow B_{1}, B_{2}, \cdots, B_{i-1}, B_{i}^{\prime}, B_{i+1}, \cdots, B_{n}\right) \\
& \text { とする. 光のとき, } \\
& \mathcal{M}(Q \cup\{C\})=\mathcal{M}\left(Q \cup\left\{C^{\prime}\right\}\right)
\end{aligned}
$$$$
\text { が成り立つ。 }
$$

\section{5. 繰り込まれた宣言的記述の等価変換}

参照記述を等価変換により簡単化し，負制約を単純な 制約に変換するための基礎を与える．なお，ここでの記 号は 4 章の定義を前提とする.

$P, Q$ を $\Gamma$ 上の制約つき宣言的記述とする．Pに属す る節が負制約 $[a \notin \mathcal{M}(Q)]$ を持つとき，前節の定理によ り，光れを負制約 $[\phi(a) \notin \mathcal{M}(Q \cup\{\phi(a) \leftarrow a\})]$ に変換 することができる.乥こで, $Q \cup\{\phi(a) \leftarrow a\}$ を等価変換 して，節集合 $\{\phi(a) \leftarrow a\}$ を単位節集合 $F$ に変換するこ とを考える．但し， $Q$ の部分は変更しないものとする . このとき，負制約 $[\phi(a) \notin \mathcal{M}(Q \cup\{\phi(a) \leftarrow a\})]$ は負制 約 $[\phi(a) \notin \mathcal{M}(Q \cup F)]$ になるが，光れをさらに依存制約 でない形に変換するための定理を考える．

まず，命題 6 を証明する .この命題の中の $F$ は $\mathcal{A}_{1}$ のア 卜ムから作られる単位節集合である。また，条件 $(\phi(b) \leftarrow$

$* 8$ 定理の証明で, $\phi(x) \in \phi(X)$ の形の条件を $x \in X$ の形の条 件に同値変形するときなどに全単射であることを用いる． 
)$\in F$ は，単位節 $\phi(b) \leftarrow$ か $F$ に含まれることを意味す る. $\bigcup_{(\phi(b) \leftarrow) \in F} r e p(b)$ は, $(\phi(b) \leftarrow) \in F$ の条件を満た す全てのアトム $b$ に対して基礎例の集合 $r e p(b)$ を考え， 乥れら全ての集合の和集合として得られる集合である．

〈命題 6〉 $\mathcal{M}(F)=\phi\left(\bigcup_{(\phi(b) \leftarrow) \in F} r e p(b)\right)$

命題 9 のために次の 2 つの命題を示す .

〈命題 7〉 $\mathcal{M}(Q \cup F) \cap \mathcal{G}_{0}=\mathcal{M}(Q)$

〈命題 8〉 $\mathcal{M}(Q \cup F) \cap \mathcal{G}_{2}=\mathcal{M}(F)$

以上より, 次の命題が得られる.

〈命題 9〉 $\mathcal{M}(Q \cup F)=\mathcal{M}(Q) \cup \mathcal{M}(F)$

これを用いれば，参照記述を等価変換により簡単化し， さらに依存制約を単純な制約に変換するための基礎とな る定理か証明できる。

[ 定理 2] (依存解消変換) $P, Q, Q^{\prime}$ を $\Gamma$ 上の制約つき 宣言的記述， $F$ は次式を満たす宣言的記述であるとする．

(1) $F$ は $\mathcal{A}_{1}$ のアトム (述語 $p_{1}$ を持つアトム) をへッ

ドとする単位節からなる集合

(2) $\mathcal{M}\left(Q \cup Q^{\prime}\right)=\mathcal{M}(Q \cup F)$

また， $B_{i}$ を負制約 $\left[\phi(a) \notin \mathcal{M}\left(Q \cup Q^{\prime}\right)\right] ， B_{i}^{\prime}$ を制約 $[a \notin$ $\left.\bigcup_{(\phi(b) \leftarrow) \in F} r e p(b)\right], C$ と $C^{\prime}$ を $\Gamma$ 上の制約つき確定節

$C=\left(H \leftarrow B_{1}, B_{2}, \cdots, B_{i-1}, B_{i}, B_{i+1}, \cdots, B_{n}\right)$

$C^{\prime}=\left(H \leftarrow B_{1}, B_{2}, \cdots, B_{i-1}, B_{i}^{\prime}, B_{i+1}, \cdots, B_{n}\right)$

とする . 光のとき ，

$\mathcal{M}(P \cup\{C\})=\mathcal{M}\left(P \cup\left\{C^{\prime}\right\}\right)$

が成り立つ。

\section{6. 等価変換による解法例}

\section{$6 \cdot 1$ 非 回文問 題}

“たけやっシやけた”のように，前から読んでも後ろから 読んでも同じ文字列を回文 (palindrome) と呼ぶ . 本節 では,,$a て ゙$ 始まり $b$ で終わるようなリストの中で，回文 であるリストが存在しない」ことを示す問題を等価変換 で解くことを考える．

この問題を，制約つき宣言的記述の意味を用いて記述 するために，宣言的記述 $P_{1}$ と光れが参照する宣言的記 述 $Q_{1}$ を次のように定義する。

$$
\begin{aligned}
& P_{1}=\left\{C_{1}\right\} \\
& C_{1}=\left(n t(X) \leftarrow\left[t(X) \notin \mathcal{M}\left(Q_{1}\right)\right]\right) \\
& Q_{1}=\left\{C_{2}, C_{3}, C_{4}, C_{5}, C_{6}, C_{7}\right\}
\end{aligned}
$$

$C_{2}: t(X) \leftarrow a p([a \mid X],[b], Z), \operatorname{pal}(Z)$.

$C_{3}: \operatorname{pal}(Z) \leftarrow \operatorname{rev}(Z, Z)$.

$C_{4}: \operatorname{rev}([],[]) \leftarrow$.

$C_{5}: \operatorname{rev}([A \mid X], Y) \leftarrow \operatorname{rev}(X, W), a p(W,[A], Y)$.

$C_{6}: \operatorname{ap}([], Y, Y) \leftarrow$.

$C_{7}: a p([A \mid X], Y,[A \mid Z]) \leftarrow a p(X, Y, Z)$.

この問題は, 宣言的記述 $P_{1}^{\prime}$ を

$P_{1}^{\prime}=P_{1} \cup\{\operatorname{ans}(X) \leftarrow n t(X)\}$

とし, $\mathcal{G}$ の部分集合 $G$ に対して集合を与える写像を
$\pi(G)=\{x \mid \operatorname{ans}(x) \in G\}$.

とするとき， $\pi\left(\mathcal{M}\left(P_{1}^{\prime}\right)\right)$ を求める問題として定式化でき る。

この問題を解くとき，次のルール*9を用いる .

$R_{1}: n t(X) \rightarrow\left[t(X) \notin \mathcal{M}\left(Q_{1}\right)\right]$.

$R_{2}: t(X) \rightarrow a p([a \mid X],[b], Z), \operatorname{pal}(Z)$.

$R_{3}: \operatorname{pal}(Z) \rightarrow \operatorname{rev}(Z, Z)$.

$R_{4}: \operatorname{rev}([A \mid X], Y) \rightarrow \operatorname{rev}(X, W), \operatorname{ap}(W,[A], Y)$.

$R_{5}: a p([A \mid X], Y, Z) \rightarrow\{Z=[A \mid Z 1]\}, a p(X, Y, Z 1)$.

$R_{6}: \operatorname{ap}(X,[A], Z), \operatorname{ap}(Y,[B], Z) \rightarrow\{X=Y, A=B\}$, $a p(X,[A], Z)$.

$R_{7}: \operatorname{ap}(X, Y,[]) \rightarrow\{X=[], Y=[]\}$.

$R_{8}: a p(X, Y,[C \mid Z]) \rightarrow\{X=[C \mid X 1]\}, a p(X 1, Y, Z)$;

$$
\rightarrow\{X=[], Y=[C \mid Z]\} .
$$

答が得られる過程を以下に示す．

$$
\begin{aligned}
& \text { p1: } \quad \operatorname{ans}(Z) \leftarrow n t(Z) . \\
& \mathrm{p} 2: \quad \operatorname{ans}(X) \leftarrow\left[t(X) \notin \mathcal{M}\left(Q_{1}\right)\right] .\left(R_{1}\right. \text { より) } \\
& \text { p3: } \quad \operatorname{ans}(X) \leftarrow\left[t^{\prime}(X) \notin \mathcal{M}\left(Q_{1} \cup Q_{1}^{\prime}\right)\right] \text {. }
\end{aligned}
$$

(繰り込み変換より)

$Q_{1}^{\prime}=\left\{t^{\prime}(X) \leftarrow t(X)\right\}$ として $t^{\prime}$ 節を変換する.

q11: $t^{\prime}(X) \leftarrow t(X)$.

q12: $\quad t^{\prime}(X) \leftarrow a p([a \mid X],[b], Z), \operatorname{pal}(Z) .\left(R_{2}\right.$ より)

q13: $\quad t^{\prime}(X) \leftarrow a p(X,[b], Z 1), \operatorname{pal}([a \mid Z 1])$.

$\left(R_{5}\right.$ より)

q14: $\quad t^{\prime}(X) \leftarrow a p(X,[b], Z 1), \operatorname{rev}([a \mid Z 1],[a \mid Z 1])$.

$$
\left(R_{3}\right. \text { より) }
$$

q15: $\quad t^{\prime}(X) \leftarrow a p(X,[b], Z 1), \operatorname{rev}(Z 1, W)$, $a p(W,[a],[a \mid Z 1]) .\left(R_{4}\right.$ より)

これは次の 2 つの節に展開される .

q16-1: $t^{\prime}(X) \leftarrow a p(X,[b], Z 1), \operatorname{rev}(Z 1,[a \mid W 1])$, $a p(W 1,[a], Z 1) .\left(R_{8}\right.$ より $)$

q16-2: $t^{\prime}(X) \leftarrow a p(X,[b],[]), \operatorname{rev}([],[]) .\left(R_{8}\right.$ より) q16-1 は q17-1，q16-2 は q17-2 になる .

q17-1: $t^{\prime}(X) \leftarrow X=W 1,[b]=[a], a p(X,[b], Z 1)$, $\operatorname{rev}(Z 1,[a \mid W 1]) . \quad\left(R_{6}\right.$ より $)$

q17-2: $t^{\prime}(X) \leftarrow X=[],[b]=[], \operatorname{rev}([],[])$.

$$
\left(R_{7}\right. \text { より) }
$$

両方の $t^{\prime}$ 節が消滅し, p3 は $\mathrm{p} 4$ になる。

$\mathrm{p} 4: \quad \operatorname{ans}(X) \leftarrow\left[t^{\prime}(X) \notin\{\}\right]$. (依存解消変換より)

p5: $\quad \operatorname{ans}(X) \leftarrow$.

よって答え $\pi\left(\mathcal{M}\left(P_{1}^{\prime}\right)\right)$ はリスト全体の集合となる .

*9 ルールのシンタックスと意味の詳細については [Akama 01c, Koike 01] を参照のこと. 
$6 \cdot 2$ 二 重 否 定

次のように二重否定を含む問題 [Chan 88] を考える.

$P_{2}=\left\{C_{1}\right\}$.

$C_{1}: p(X) \leftarrow\left[q(X) \notin \mathcal{M}\left(Q_{2}\right)\right]$.

$Q_{2}=\left\{C_{2}\right\}$.

$C_{2}: q(X) \leftarrow\left[r(X) \notin \mathcal{M}\left(Q_{3}\right)\right]$.

$Q_{3}=\left\{C_{3}, C_{4}\right\}$.

$C_{3}: r(1) \leftarrow$.

$C_{4}: r(2) \leftarrow$.

この問題に質問 $q(X)$ を与えると， $X \neq 1, X \neq 2$ が得

られる．また，質問 $p(X)$ を与えると， $p(1)$ と $p(2)$ が 得られる .

\section{$6 \cdot 3$ 一階述語論理式}

否定があれば一階述語論理式が導入できる．例えば， [Chan 88] をもとに，次のような宣言的記述を考える． $P_{3}=\left\{C_{1}, C_{2}, C_{3}, C_{4}, C_{5}, C_{6}, C_{7}\right\}$.

$C_{1}$ : like $($ mary,$X) \leftarrow \forall Y:[$ wants $(\operatorname{mary}, Y)$ $\rightarrow \operatorname{gives}(X, Y, \operatorname{mary})]$.

$C_{2}:$ wants $($ mary,$a) \leftarrow$.

$C_{3}:$ wants $($ mary,$b) \leftarrow$.

$C_{4}: \operatorname{gives}($ john,$a) \leftarrow$.

$C_{5}:$ gives $(j o h n, c) \leftarrow$.

$C_{6}: \operatorname{gives}(j a c k, a) \leftarrow$.

$C_{7}: \operatorname{gives}(j a c k, b) \leftarrow$.

このとき，質問 $\operatorname{like}(\operatorname{mar} y, X)$ を与えると，

like (mary,jack) が得られる .これは, 本論文の否定計 算を基に導入された一階述語制約による [Yoshida 98] .

\section{7. 論理パラダイムとの比較}

\section{$7 \cdot 1$ SLDNFレゾリューションとの比較}

非回文問題をSLDNFレゾリューションで解くことを 考える . 問い合わせ $\leftarrow n t(Z)$ を与えると，

$$
\leftarrow \neg t(X)
$$

と変形されるが, SLDNFレゾリューションではこれ以 上計算を進めることができない . なぜならば, SLDNF レゾリューションは変数の入った負のリテラルを選択す ることを禁止しているからである . 負のリテラルを選択 すれば計算の正当性が保証できない [Lloyd 87, Apt 94] 一方，前章で見たように，本論文の等価変換に基づく方 法はこの困難を克服している．

本論文の理論から，SLDNF レゾリューションの正当 性を導くことができる．本論文の定理1において，aは $\Gamma$ 上の任意のオブジェクトである．「压項領域の特殊化シ ステムにするとき， $a$ は任意のアトムとなる .これを任 意の基礎アトムに制限した定理を定理 1'とする . また , $a$ が基礎アトムであるとき，定理 2 の集合 $F$ は $\{\phi(a)\}$ ま たは空集合となる．光して $B_{i}^{\prime}$ は恒真か恒偽である．光 のような場合に特化した定理 2 を定理 2 'とする . これら
の定理 1'と定理 2' に基づいた等価変換ルールを使い，通 常のアトムはアンフォールド変換で処理すれば, SLDNF レゾリューションか許している範囲の計算が可能となる . これらの変換はすべて等価変換であるから, SLDNFレ ゾリューションの計算の (等価変換の意味での) 正当性は 明らかである .

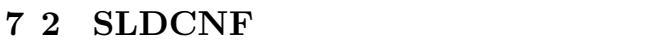

SLDNFレゾリューションの限界を克服する目的でな された研究に, 構成的否定の研究 [Chan 88, Chan 89] がある.例えば SLDCNF レゾリューションでは，変数 の含まれた負リテラルを選択して計算を進め，負のゴー ルからも束縛を得ることができる．

本研究との関係を述べる. 本論文の等価変換ルールを 項の領域に適用して，いくつかの等価変換ルールを追加 すれば , [Chan 88] に出現するすべての例題 (否定のサブ ゴールを計算して制約を得る例題，全称束縛されたサブ ゴールを解く例題，構成的否定を用いて計算効率を上げ る例題など) を解くことができる．また，[Chan 88]の発 展である [Chan 89] にあるような否定のサブゴールの計 算が無限に続くことによる困難を，他の計算と関係させ ながら少しずつ計算 (コルーチン) して解決することも可 能である .

本論文の等価変換ルールに非等式制約*10 を処理する 等価変換ルールを付け加えれば, SLDCNF レゾリュー ション (の計算) が (等価変換の意味で) 正当であること を証明することができる．

逆に, SLDCNF レゾリューションの正当性 (健全性と 完全性) を示す定理を用いても，個々の等価変換にあた る計算の正当性を証明することはできない．レゾリュー ションの枠組みには, 全体の計算の正当性の概念しかな いからである .この意味で，等価変換パラダイムに基づ く理論体系は，レゾリューションに基づく理論体系より も真に強力である .

具体的な例題で議論する. 6 章の非回文問題を等価変換 で解くことができるが，この問題を解くためのサブゴー ル $t(X)$ の計算は実際には見かけほど簡単ではない . 例 えばアンフォールド変換ルールを使えば rev アトムや $a p$ アトムが無限に展開される恐れがある．無限に展開され ずに $t(X)$ の答えがないことを示すためには，適切な制 御と， $R_{6}$ にあたる処理が必要である．通常の SLD レゾ リューションはこの解決を与えることは困難であり，従っ て，SLDCNF レゾリューションでも同樣に困難である . このように，否定を含んでいない問題が十分解決できな ければ，結局否定を含んだ問題を実際的に解決すること はできない．この点でも，等価変換の多樣性と部品の自 由な採用に基づく等価変換パラダイムの優位性は摇るが ない．

\footnotetext{
$* 10$ 定理 2 の $B_{i}^{\prime}$ は項の領域では非等式制約を用いて書くことが できる. 例えば, $X \notin \operatorname{rep}(d)$ は $X \neq d$ と書ける .
} 


\section{$7 \cdot 3$ その他の研究との比較}

論理パラダイムでは, 制約論理プログラムや一階述語論 理や非単調推論などさまざまな方向への拡張か論じられて おり，否定に関連する議論も多いが [Stucky 95, Sato 91, Barbuti 90, Drabent 93] , 最も単純な確定節レベルの計 算の問題 (制御など) が十分解決しなければ 実際的に解決 できる範囲は広くはならないという意味ではSLDCNFレ ゾリューションと同樣の問題を抱えていると考えられる .

\section{8.む す び}

等価変換パラダイムでは, プログラムを，等価変換ルー ルという部品から構築することができる . これは , プロ グラム生成にとって最も重要な性質であろう．本論文で は，等価変換パラダイムのこの著しい利点をさらに広く 利用可能とするために，等価変換パラダイムを否定を含 む問題に適用するための基礎的な枠組みを提案した .

本論文の定理から，2つの等価変換ルールを作ること ができる．定理 1 から，制約対象の情報を参照記述の中 に繰り込むルールが得られる．こうして得られた宣言的 記述を等価変換して単位節の集合が得られた場合，弚の 情報を呼びだし側の簡単な制約として返すルールが定理 2 から得られる .この 2 つのルールは, 負制約の計算に対 する基礎的なルールである .これらのルールは , Prolog の「失敗による否定」とは対照的に，否定されるアトム が変数を含むか否かには無関係に正当である．

等価変換による否定の計算 (上記の情報交換のルール を含めて) は，すでに等価変換プログラミング言語 ETC [清水 96] で実現されている．ETC を用いて，自然言語 理解システムが実現されており [吹田 97] , 否定の正当で 高速な計算は, システム作成の重要な鍵となっている .

\section{$\diamond$ 参 考 文 献 $\diamond$}

[赤間 97] 赤間清，繁田良則，宮本衛市: 論理プログラムの等価 変換による問題解決の枠組, 人工知能学会誌, Vol.12, No.2, pp.90-99 (1997).

[赤間 98a] 赤間清，繁田良則，宮本衛市: 特殊化システムの拡 張による知識表現系の変更, 人工知能学会誌, Vol.13, No.1, pp.341-349 (1998).

[赤間 98b] 赤間清， 川口 雄一，宮本衛市: 項領域における包含 制約の等価変換, 人工知能学会誌, Vol.13, No.2, pp.112-120 (1998)

[赤間 98c] 赤間清 , 川口雄一, 宮本衛市: マルチセット領域上の等 式制約の等価变換, 人工知能学会誌, Vol.13, No.3, pp.395-403 (1998)

[赤間 98d] 赤間清, 川口 雄一, 宮本衛市: 論理的問題の等価変 換による解法 (2), SLD 導出の限界, 人工知能学会誌, Vol.13, No.6, pp.936-943 (1998).

[赤間 98e] 赤間清, 清水伴訓, 宮本衛市: 宣言的プログラムの等 価変換による問題解決, 人工知能学会誌, Vol.13, No.6, pp.944952 (1998)

[Akama 01a] Akama, K., Koike, H., and Mabuchi, H.: A Foundation of Program Synthesis based on Separated Descriptions, 2001 IEEE International Conference on Intelligent Engineering Systems (INES 2001), pp.143-148, (2001).
[Akama 01b] Akama, K., Koike, H., and Ishikawa, T.: Semantics for Declarative Descriptions with Referential Constraints, International Conference on Computing and Information Thchnologies (ICCIT 2001), pp.405-410 (2001).

[Akama 01c] Akama, K., Nantajeewarawat, E., and Koike, H.: A Class of Rewriting Rules and Reverse Transformation for Rule-Based Equivalent Transformation, Electronic Notes in Theoretical Computer Science, 59 No.4 pp.1-16 (2001).

[Apt 94] Apt, K.R. and Bol, R.N.: Logic Programming and Negation: a survey, Journal of logic programming, Vol. 19 and 20, pp.9-71 (1994).

[Barbuti 90] Barbuti, B., Mancarella, P., Pedreschi, D., and Turini, F.: A Transformational Approach to Negation in Logic Programming, Journal of Logic Programming, Vol.8, pp.201-228 (1990).

[Chan 88] Chan, D.: Constructive Negation Based on the Completed Database, Proc. of ICLP-88, pp.111-125 (1988).

[Chan 89] Chan, D.: An Extension of Constructive Negation and Its Application in Coroutining, Proc. of NACLP-89, pp.477-493 (1989).

[Drabent 93] Drabent, W.: SLS-Resolution without Floundering, Proc. of LPNMR-93, pp.82-98 (1993).

[畑山 97] 畑山満美子, 赤間清, 宮本衛市: 等価変換ルールの追加 による知識処理システムの改善, 人工知能学会誌, Vol.12, No.6, pp.861-869 (1997).

[Koike 00] Koike, H., Akama, K., Mabuchi, H., and Shigeta, Y.: Rule Generation by Meta-computation, the 6th International Conference on Information Systems Analysis and Synthesis (ISAS2000), Orlando, USA, in July 23-26, pp.429434 (2000).

[Koike 01] Koike, H., Akama, K., and Boyd, E.: Program Synthesis by Generating Equivalent Transformation Rules, in Proceedings of the Second International Conference on Intelligent Technologies (InTech'01), Bangkok, Thailand, pp.250-259 (2001).

[Lloyd 87] Lloyd, J.W.: Foundations of Logic Programming, Second Edition, Springer-Verlag (1987).

[Sato 91] Sato, T. and Motoyoshi, F.: A Complete Top-down Interpreter for First Order Programs, Proc. of ICLP-91, pp.35-53 (1991).

[清水 96] 清水伴訓, 赤間清, 宮本衛市: 等価変換プログラミング 言語 ETC, 電子情報通信学会 技術研究報告, SS 96-19, pp.9-16 (1996).

[Stucky 95] Stucky, P.J.: Negation and Constraint Logic Programming, Information and Computation, Vol.118, No.1, pp.12-33 (1995).

[吹田 97] 吹田慶子, 赤間清, 宮本衛市: 等価変換に基づく自然 言語理解システムの構築, 電子情報通信学会 技術研究報告, SS 97-35, pp.23-30 (1997).

[辻 99] 辻 武士, 赤間 清, 宮本 衛市: 条件を満たす項の集合 の表現と計算, 電子情報通信学会技術研究報告 SS99-5, pp.1-8 (1999).

[Wuwongse 01] Wuwongse, V., Anutariya, C., Akama, K., and Nantajeewarawat, E.: XML Declarative Description: A Language for the Semantic Web, IEEE Intelligent Systems, pp.54-65, MAY/JUNE (2001).

[Yoshida 98] Yoshida, T., Akama, K., and Miyamoto, E.: Problem Solving by Equivalent Transformation of First Order Logical Constraints, Preprints Work. Gr. for ICS 98ICS-114-2, pp7-12 (1998).

\section{〔担当委員：佐藤 健〕}

2001 年 8 月 24 日 受理 


\section{$\diamond$ 付 録 $\diamond$}

\section{A. [特殊化システムの定義について]}

通常，代入は項を变化させる写像として扱われる。しかし厳密に は, 代入は (束縛, 即ち, 変数と項のペアの) 集合であって, 写像 ではない，従って，代入の決める写像を与えるための写像 $\mu$ が必 要になる. 特殊化システムの定義においても，特殊化 $s$ と乥れが決 める部分写像 $\mu(s)$ を概念的に区別することは重要である . 例えば， ある問題を解くために特殊化システムを構筑するとき， $\mathcal{A}$ 上の部

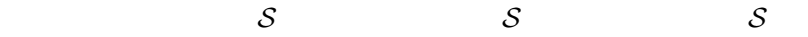
要素である特殊化 $s$ に対応する部分写像をある写像 $\mu$ で指定する 方が自然である場合が多い．

代入は項を変化させる写像を決める .しかし特殊化は，一般には， 写像ではなく部分写像を決める必要がある. 例えば, 犬である $X$ を意味する $X: \operatorname{dog}$ に代入 $\{X /$ ポチ $\}$ を適用できる．しかし犬で ある $X: \operatorname{dog}$ は猫であるミケになれないから，代入 $\{X /$ ミケ $\}$ は 適用できない .

\section{B. [命題と 定理の証明]}

以下で用いる補題は付録 C で証明する

(1) 命題 1 の証明.論文 [赤間 98b] 参照 .

(2) 命題 2 の証明.命題 1 より, 任意の $x \subseteq \mathcal{G}$ に対して $T_{\{C\}}(x)=$ $T_{\left\{C^{\prime}\right\}}(x)$ を示せば良い. $T_{\{C\}}(x)$ は $C$ の基礎例のへッド, ボ ディアトム，制約によって決まる．これを $T_{\left\{C^{\prime}\right\}}(x)$ と比較する と，制約 $B_{i}=(a, G)$ か制約 $B_{i}^{\prime}=\left(a^{\prime}, G^{\prime}\right)$ に置き換えられたと ころだけが異なる.しかし仮定により， $a \theta \in G$ と $a^{\prime} \theta \in G^{\prime}$ が同 值なので, 弚れらが $T_{\{C\}}(x)$ と $T_{\left\{C^{\prime}\right\}}(x)$ で光れ光れ果たす役 割は同じであり，任意の $x \subseteq \mathcal{G}$ に対して $T_{\{C\}}(x)=T_{\left\{C^{\prime}\right\}}(x)$ であることがわかる .

(3) 命題 3 の証明 .

$$
\begin{aligned}
\mathcal{M}(Q) & \cup\{\phi(a) \leftarrow a\}) \cap \mathcal{G}_{0} \\
& =\mathcal{M}\left(Q \cup Q^{\prime}\right) \cap \mathcal{G}_{0} \\
& =\left(\cup_{n=1}^{\infty}\left[T_{Q \cup Q^{\prime}}\right]^{n}(\emptyset)\right) \cap \mathcal{G}_{0} \\
& =\cup_{n=1}^{\infty}\left(\left[T_{Q \cup Q^{\prime}}\right]^{n}(\emptyset) \cap \mathcal{G}_{0}\right) \\
& =\cup_{n=1}^{\infty}\left[T_{Q}\right]^{n}(\emptyset) \quad(\text { 補題 } 1) \\
& =\mathcal{M}(Q)
\end{aligned}
$$

(4) 命題 4 の証明

$$
\begin{aligned}
\mathcal{M}(Q & \cup\{\phi(a) \leftarrow a\}) \cap \mathcal{G}_{2} \\
& =\mathcal{M}\left(Q \cup Q^{\prime}\right) \cap \mathcal{G}_{2} \\
& =\left(\cup_{n=1}^{\infty}\left[T_{Q \cup Q^{\prime}}\right]^{n}(\emptyset)\right) \cap \mathcal{G}_{2} \\
& =\cup_{n=1}^{\infty}\left(\left[T_{Q \cup Q^{\prime}}\right]^{n}(\emptyset) \cap \mathcal{G}_{2}\right) \\
& =\cup_{n=1}^{\infty} \phi\left(\left[T_{Q}\right]^{n-1}(\emptyset) \cap \operatorname{rep}(a)\right) \quad\left(\text { 補題 2) }^{\infty}\right) \\
& =\phi\left(\cup_{n=1}^{\infty}\left(\left[T_{Q}\right]^{n-1}(\emptyset) \cap \operatorname{rep}(a)\right)\right) \\
& =\phi\left(\left(\cup_{n=1}^{\infty}\left[T_{Q}\right]^{n-1}(\emptyset)\right) \cap \operatorname{rep}(a)\right) \\
& =\phi(\mathcal{M}(Q) \cap \operatorname{rep}(a))
\end{aligned}
$$

(5) 命題 5 の証明. $\mathcal{M}(Q \cup\{\phi(a) \leftarrow a\}) \subseteq \mathcal{G}_{0} \cup \mathcal{G}_{2}$ だから ,

$$
\begin{aligned}
& \mathcal{M}(Q \cup\{\phi(a) \leftarrow a\}) \\
&=\left(\mathcal{M}(Q \cup\{\phi(a) \leftarrow a\}) \cap \mathcal{G}_{0}\right) \\
& \cup\left(\mathcal{M}(Q \cup\{\phi(a) \leftarrow a\}) \cap \mathcal{G}_{2}\right)
\end{aligned}
$$

これは, 命題 3 と命題 4 より, $\mathcal{M}(Q) \cup \phi(\mathcal{M}(Q) \cap \operatorname{rep}(a))$ に 等しい.

(6) 定理 1 の証明 . $\theta \in \mathcal{S}$ と仮定する . $\phi(a) \theta \in \mathcal{A}_{2}, \mathcal{M}(Q) \subseteq$ $\mathcal{A}_{0}, \mathcal{A}_{2} \cap \mathcal{A}_{0}=\emptyset$ より $\phi(a) \theta \notin \mathcal{M}(Q)$ が成り立つ. 命題 5 , $\phi(a) \theta \notin \mathcal{M}(Q), \phi(a) \theta=\phi(a \theta), \phi$ が全単射であること,$a \theta \in$ $r e p(a)$ などにより , 次のように同值変形できる . $\phi(a) \theta \in \mathcal{M}\left(Q \cup Q^{\prime}\right)$

$\Longleftrightarrow \phi(a) \theta \in \mathcal{M}(Q) \cup \phi(\mathcal{M}(Q) \cap \operatorname{rep}(a))$

$\Longleftrightarrow \phi(a \theta) \in \phi(\mathcal{M}(Q) \cap r e p(a))$

$\Longleftrightarrow a \theta \in \mathcal{M}(Q) \cap \operatorname{rep}(a)$

$$
\Longleftrightarrow a \theta \in \mathcal{M}(Q)
$$

よって, $\phi(a) \theta \in \mathcal{M}\left(Q \cup Q^{\prime}\right)$ と $a \theta \in \mathcal{M}(Q)$ は等価である. $\phi(a) \theta \in \mathcal{G}$ と $a \theta \in \mathcal{G}$ も等価であるから,$\phi(a) \theta \in \mathcal{G}-\mathcal{M}(Q \cup$ $\left.Q^{\prime}\right)$ と $a \theta \in \mathcal{G}-\mathcal{M}(Q)$ も等価である. 命題 2 より，

$$
\mathcal{M}(P \cup\{C\})=\mathcal{M}\left(P \cup\left\{C^{\prime}\right\}\right)
$$

が成り立つ。
(7) 命題 6 の証明 . $\phi$ は全単射であるから,

$$
\begin{aligned}
\mathcal{M}(F) & =\bigcup_{(u \leftarrow) \in F} \operatorname{rep}(u) \\
& =\phi\left(\bigcup_{(\phi(b) \leftarrow) \in F} \operatorname{rep}(b)\right) .
\end{aligned}
$$

(8) 命題 7 の証明 .

$$
\mathcal{M}(Q \cup F) \cap \mathcal{G}_{0}
$$

$$
\begin{aligned}
& =\left(\cup_{n=1}^{\infty}\left[T_{Q \cup F}\right]^{n}(\emptyset)\right) \cap \mathcal{G}_{0} \\
& =\cup_{n=1}^{\infty}\left(\left[T_{Q \cup F}\right]^{n}(\emptyset) \cap \mathcal{G}_{0}\right) \\
& =\cup_{n=1}^{\infty}\left[T_{Q}\right]^{n}(\emptyset) \quad(\text { 補題 3) } \\
& =\mathcal{M}(Q)
\end{aligned}
$$

(9) 命題 8 の証明 .

$\mathcal{M}(Q \cup F) \cap \mathcal{G}_{2}$

$$
\begin{aligned}
& =\left(\cup_{n=1}^{\infty}\left[T_{Q \cup F}\right]^{n}(\emptyset)\right) \cap \mathcal{G}_{2} \\
& =\cup_{n=1}^{\infty}\left(\left[T_{Q \cup F}\right]^{n}(\emptyset) \cap \mathcal{G}_{2}\right) \\
& =\cup_{n=1}^{\infty} \mathcal{M}(F) \quad(\text { 補題 } 4) \\
& =\mathcal{M}(F)
\end{aligned}
$$

(10) 命題 9 の証明. 命題 7 と命題 8 より,

$$
\begin{aligned}
& \mathcal{M}(Q \cup F) \\
& \quad=\left(\mathcal{M}(Q \cup F) \cap \mathcal{G}_{0}\right) \cup\left(\mathcal{M}(Q \cup F) \cap \mathcal{G}_{2}\right) \\
& =\mathcal{M}(Q) \cup \mathcal{M}(F) .
\end{aligned}
$$

(11) 定理 2 の証明. $\theta \in \mathcal{S}$ を仮定する . 命題 $9, \phi(a) \theta \notin \mathcal{M}(Q)$, $\phi$ は全単射であること, 命題 6 などにより， $\phi(a) \theta \in \mathcal{M}\left(Q \cup Q^{\prime}\right)$

$$
\begin{aligned}
& \Longleftrightarrow \phi(a) \theta \in \mathcal{M}(Q \cup F) \quad \text { (仮定より) } \\
& \Longleftrightarrow \phi(a) \theta \in \mathcal{M}(Q) \cup \mathcal{M}(F) \\
& \Longleftrightarrow \phi(a) \theta \in \mathcal{M}(F) \\
& \Longleftrightarrow a \theta \in \phi^{-1}(\mathcal{M}(F)) \\
& \Longleftrightarrow a \theta \in \bigcup_{(\phi(b) \leftarrow) \in F} r e p(b)
\end{aligned}
$$

よって, $\phi(a) \theta \in \mathcal{M}\left(Q \cup Q^{\prime}\right)$ と $a \theta \in \bigcup_{(\phi(b) \leftarrow) \in F} r e p(b)$ は 等価である. $\phi(a) \theta \in \mathcal{G}$ と $a \theta \in \mathcal{G}$ も等価であるから， $\phi(a) \theta \in$ $\mathcal{G}-\mathcal{M}\left(Q \cup Q^{\prime}\right)$ と $a \theta \in \mathcal{G}-\bigcup_{(\phi(b) \leftarrow) \in F} r e p(b)$ も等価にな

る.故に命題 2 より， $\mathcal{M}(P \cup\{C\})=\mathcal{M}\left(P \cup\left\{C^{\prime}\right\}\right)$ が成り立つ。

\section{C. [補題とその証明 $]$}

[ 補題 1] 任意の $n \geq 0$ に対して, $\left[T_{Q \cup Q^{\prime}}\right]^{n}(\emptyset) \cap \mathcal{G}_{0}=\left[T_{Q}\right]^{n}(\emptyset)$

証明. 帰納法で証明する。

(1) $n=0$ のとき, $\left[T_{Q \cup Q^{\prime}}\right]^{0}(\emptyset) \cap \mathcal{G}_{0}=\left[T_{Q}\right]^{0}(\emptyset)$ を示せばよい が, $\left[T_{Q \cup Q^{\prime}}\right]^{0}(\emptyset)=\left[T_{Q}\right]^{0}(\emptyset)=\emptyset$ より明らか.

(2) 非負整数 $k$ に対して $\left[T_{Q \cup Q^{\prime}}\right]^{k}(\emptyset) \cap \mathcal{G}_{0}=\left[T_{Q}\right]^{k}(\emptyset)$ を仮 定して , $\left[T_{Q \cup Q^{\prime}}\right]^{k+1}(\emptyset) \cap \mathcal{G}_{0}=\left[T_{Q}\right]^{k+1}(\emptyset)$ を証明する.$g \in$ $\left[T_{Q \cup Q^{\prime}}\right]^{k+1}(\emptyset) \cap \mathcal{G}_{0}$ を以下のように等価変換する .

$\Longleftrightarrow \exists \theta, H, B_{i}(1 \leq i \leq m)$ :

$$
\begin{aligned}
& \left(H \leftarrow B_{1}, B_{2}, \cdots, B_{m}\right) \in Q \cup Q^{\prime}, \\
& g=H \theta, \\
& B_{i} \theta \in\left[T_{Q \cup Q^{\prime}}\right]^{k}(\emptyset) \quad(1 \leq i \leq m), \\
& g \in \mathcal{G}_{0} . \\
& \exists, H, B_{i}(1 \leq i \leq m): \\
& \left(H \leftarrow B_{1}, B_{2}, \cdots, B_{m}\right) \in Q, \\
& g=H \theta, \\
& B_{i} \theta \in\left[T_{Q \cup Q^{\prime}}\right]^{k}(\emptyset) \cap \mathcal{G}_{0} \quad(1 \leq i \leq m) . \\
& \theta, H, B_{i}(1 \leq i \leq m): \\
& \left(H \leftarrow B_{1}, B_{2}, \cdots, B_{m}\right) \in Q, \\
& g=H \theta, \\
& B_{i} \theta \in\left[T_{Q}\right]^{k}(\emptyset) \quad(1 \leq i \leq m), \quad(\text { 仮定より). }
\end{aligned}
$$$$
\Longleftrightarrow \exists \theta, H, B_{i}(1 \leq i \leq m) \text { : }
$$$$
\Longleftrightarrow \exists \theta, H, B_{i}(1 \leq i \leq m) \text { : }
$$

$\Longleftrightarrow g \in\left[T_{Q}\right]^{k+1}(\emptyset)$.

[ 補題 2] 任意の $n \geq 1$ に対して,

$\left[T_{Q \cup Q^{\prime}}\right]^{n}(\emptyset) \cap \mathcal{G}_{2}=\phi\left(\left[T_{Q}\right]^{n-1}(\emptyset) \cap \operatorname{rep}(a)\right)$

証明. $g \in\left[T_{Q \cup Q^{\prime}}\right]^{n}(\emptyset) \cap \mathcal{G}_{2}$ を等価変換する .

$\Longleftrightarrow \exists \theta, H, B_{i}(1 \leq i \leq m)$ :

$\left(H \leftarrow B_{1}, B_{2}, \cdots, B_{m}\right) \in Q \cup Q^{\prime}$, 


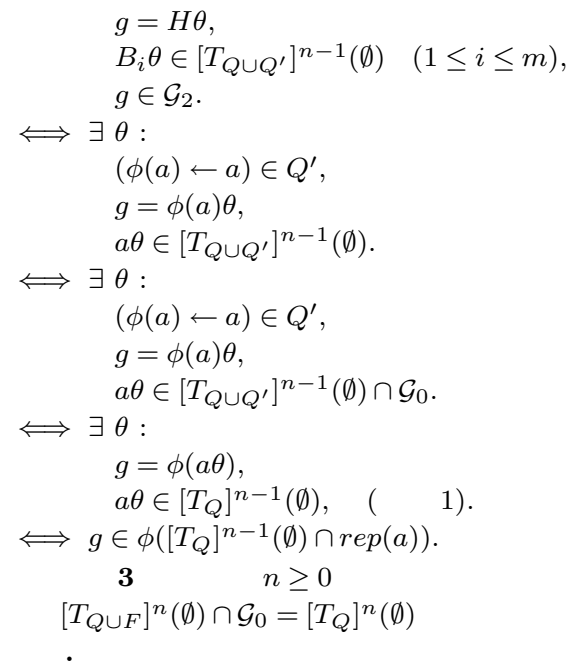

(1) $n=0$ のとき, $\left[T_{Q \cup F}\right]^{0}(\emptyset) \cap \mathcal{G}_{0}=\left[T_{Q}\right]^{0}(\emptyset)$ を示せばよい . これは, $\left[T_{Q \cup F}\right]^{0}(\emptyset)=\left[T_{Q}\right]^{0}(\emptyset)=\emptyset$ より明らか .

(2) 非負整数 $k$ に対して $\left[T_{Q \cup F}\right]^{k}(\emptyset) \cap \mathcal{G}_{0}=\left[T_{Q}\right]^{k}(\emptyset)$ を仮定し, $\left[T_{Q \cup F}\right]^{k+1}(\emptyset) \cap \mathcal{G}_{0}=\left[T_{Q}\right]^{k+1}(\emptyset)$ を証明する.

$g \in\left[T_{Q \cup F}\right]^{k+1}(\emptyset) \cap \mathcal{G}_{0}$ を以下のように等価変換する . $\Longleftrightarrow \exists \theta, H, B_{i}(1 \leq i \leq m)$ :

$\left(H \leftarrow B_{1}, B_{2}, \cdots, B_{m}\right) \in Q \cup F$, $g=H \theta$,

$B_{i} \theta \in\left[T_{Q \cup F}\right]^{k}(\emptyset) \quad(1 \leq i \leq m)$, $g \in \mathcal{G}_{0}$.

$\Longleftrightarrow \exists \theta, H, B_{i}(1 \leq i \leq m)$ :

$\left(H \leftarrow B_{1}, B_{2}, \cdots, B_{m}\right) \in Q$,

$g=H \theta$,

$B_{i} \theta \in\left[T_{Q \cup F}\right]^{k}(\emptyset) \cap \mathcal{G}_{0} \quad(1 \leq i \leq m)$.

$\Longleftrightarrow \exists \theta, H, B_{i}(1 \leq i \leq m)$ :

$$
\begin{aligned}
& \left(H \leftarrow B_{1}, B_{2}, \cdots, B_{m}\right) \in Q, \\
& g=H \theta, \\
& B_{i} \theta \in\left[T_{Q}\right]^{k}(\emptyset) \quad(1 \leq i \leq m), \quad(\text { 仮定より). }
\end{aligned}
$$

$\Longleftrightarrow g \in\left[T_{Q}\right]^{k+1}(\emptyset)$.

[ 補題 4] 任意の $n \geq 1$ に対して

$\left[T_{Q \cup F}\right]^{n}(\emptyset) \cap \mathcal{G}_{2}=\mathcal{M}(F)$

証明. $\quad g \in\left[T_{Q \cup F}\right]^{n}(\emptyset) \cap \mathcal{G}_{2}$ を等価変換する.

$\Longleftrightarrow \exists \theta, H, B_{i}(1 \leq i \leq m):$

$\left(H \leftarrow B_{1}, B_{2}, \cdots, B_{m}\right) \in Q \cup F$,

$g=H \theta$,

$B_{i} \theta \in\left[T_{Q \cup F}\right]^{n-1}(\emptyset) \quad(1 \leq i \leq m)$,

$\Longleftrightarrow \exists \theta$ :

$$
g \in \mathcal{G}_{2} \text {. }
$$

$(\phi(b) \leftarrow) \in F$,

$g=\phi(b \theta) \in \mathcal{G}_{2}$.

$\Longleftrightarrow g \in \phi\left(\bigcup_{(\phi(b) \leftarrow) \in F} r e p(b)\right)$.

$\Longleftrightarrow g \in \mathcal{M}(F)$.
著 者 紹 介

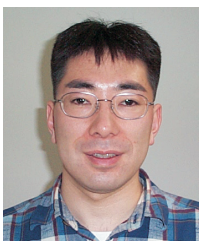

\section{小池 英勝}

1997 年北海道大学大学院工学研究科システム情報工学専 攻修士課程修了。現在, 同博士課程在学中. 等価变換によ る問題解決，知識処理の研究に従事 .

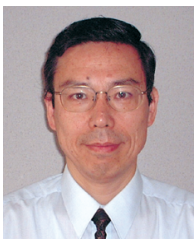

\section{赤間 清(正会員)}

1973 年東京工業大学工学部制御工学科卒. 1975 年同大 大学院修士課程修了. 1979 年同大大学院博士課程単位修 得退学. 同年, 同大学助手. 1981 年北海道大学文学部講 師. 1989 年同大学工学部助教授. 1999 年より同大学情 報メディア教育研究総合センター教授として現在に至る。 人工知能, 知識処理, 等価変換に基づく問題解決の研究に 従事. 工学博士.ソフトウエア科学会, 情報処理学会, 各 会員.

\section{馬淵 浩司(正会員)}

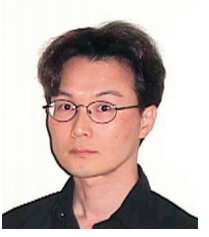

1992 年北海道大学大学院工学研究科情報工学専攻修士課 程修了. 1995 年同大学院博士後期課程修了. 同年, 東和 大学工学部電気工学科講師. 1998 年岩手県立大学ソフト ウェア情報学部講師, 現在に至る . 博士 (工学) . 人工知能, 特に問題解決と学習の研究に従事 .

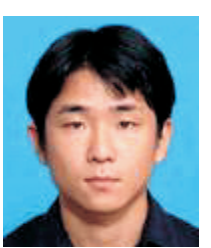

\section{岡田 浩一}

1997 年北海道大学大学院工学研究科システム情報工学専 攻修士課程修了.同年, 日本電信電話株式会社に入社 . 現 在, 情報流通プラットフォーム研究所において情報セキュ リティの研究開発に従事.

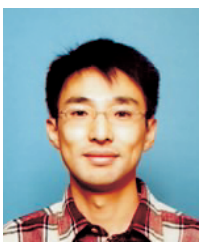

\section{繁田 良則}

1995 年北海道大学大学院工学研究科情報工学専攻博士課 程修了. 同年, 株式会社東芝に入社. 現在, システム LSI 開発センターにおいて LSI の研究開発に従事。 